\title{
Derin Öğrenme ve İstatistiksel Modelleme Yöntemiyle Sıcaklık Tahmini ve Karşılaştırılması
}

\author{
Aynur Sevinç ${ }^{1 *}$, Buket Kaya ${ }^{2}$ \\ $1^{*}$ Dicle Üniversitesi, Silvan Meslek Yüksekokulu, Diyarbakır, Türkiye, (ORCID: 0000-0002-1388-2554), sevnc.aynur03@gmail.com \\ 2 Fırat Üniversitesi, Elazığ Organize Sanayi Bölgesi MYO, Elektronik ve Otomasyon Bölümü, Elazığ, Türkiye (ORCID: 0000-0001-9505-181X), bkaya@firat.edu.tr
}

(1st International Conference on Applied Engineering and Natural Sciences ICAENS 2021, November 1-3, 2021)

(DOI: 10.31590 /ejosat.1014106)

ATIF/REFERENCE: Sevinç, A. \& Kaya, B. (2021). Derin Öğrenme ve İstatistiksel Modelleme Yöntemiyle Sıcaklık Tahmini ve Karş1laştırılması. Avrupa Bilim ve Teknoloji Dergisi, (28), 1222-1228.

\section{Öz}

Hava sıcaklığı tahmininin son yıllarda özellikle tarıma dayalı ekonomileriyle öne çıkan ülkeler için yüksek doğruluk içermesi önemlidir. Sürekli değişen hava şartları nedeniyle tahmin daha karmaşık hale gelmektedir. Bazı matematiksel ve istatistiksel teknikler sıcaklık tahmini sağlamada yetersiz olabilmektedir. Bu noktada derin öğrenme yöntemleri bu süreci daha başarılı hale getirmede son yıllarda kabul gören popüler yöntemler olarak karşımıza çıkmaktadır. Etkili bir iklim analizi gerçekleştiren derin yöntemler ile başarılı hava tahmini çalışmaları yapılabilmektedir. Bu makalenin amacı, meteorolojik verilere dayalı hava sıcaklığı tahmini için çeşitli derin öğrenme ve zamansal seri analizi yöntemlerinin uygulanabilirliğini göstermek ve performans sonuçlarını karşılaştırmaktır. Bu çalışmanın gerçekleştirilmesi için Türkiye'nin Doğu Anadolu Bölgesi’nde yer alan Bingöl ilinin Solhan ilçesine ait meteorolojik veriler kullanılarak, derin sinir ağı Uzun Kısa Süreli Bellek (LSTM) ve Otoregresif Entegre Hareketli Ortalama (ARIMA) modelleri ile analizler yapılmıştır. Gerçek veri kümesi üzerinde yapılan deney sonuçlarında geleceğe yönelik sıcaklık tahmininde başarılı sonuçlar elde edilmiştir. Bu modellerin tahmine dayalı performansları farklı değerlendirme metrikleri kullanılarak karşılaştırılmıştır. Gerçek değerler ile tahmini değerler arasındaki ilişkiyi gösteren R kare skoru değeri LSTM ağlarında 0.95, ARIMA modelinde ise 0.97 olarak hesaplanmıştır. Modellerin tahmin doğruluğunun yüksek olması, sıcaklık zaman serisi tahmini çalışmalarında bu modellerin başarılı bir şekilde uygulanabileceğini göstermiştir.

Anahtar Kelimeler: Hava sıcaklığı, Zaman serisi tahmini, Makine öğrenmesi, Derin öğrenme, LSTM, ARIMA.

\section{Temperature Estimation and Comparison with Deep Learning and Statistical Modeling Method}

\begin{abstract}
It is important that the air temperature forecast includes high accuracy, especially for countries that have come to the fore with their agriculture-based economies in recent years. Forecasting becomes more complex due to constantly changing weather conditions. Some mathematical and statistical techniques may be insufficient to provide temperature estimation. At this point, deep learning methods emerge as popular methods that have been accepted in recent years in making this process more successful. Successful weather forecasting studies can be done with deep methods that perform an effective climate analysis. The purpose of this article is to demonstrate the applicability of various deep learning and temporal series analysis methods for air temperature prediction based on meteorological data and compare the performance results. In order to carry out this study, analyzes were made with deep neural network Long Short Term Memory (LSTM) and Autoregressive Integrated Moving Average (ARIMA) models, using meteorological data from Solhan district of Bingöl province in the Eastern Anatolia Region of Turkey. In the results of the experiments on the real data set, successful results were obtained in the prediction of the future temperature. The predictive performance of these models was compared using different evaluation metrics. The R square score value, which shows the relationship between the actual values and the estimated values, was calculated as 0.95 in the LSTM networks and 0.97 in the ARIMA model. The high estimation accuracy of the models has shown that these models can be successfully applied in temperature time series estimation studies.
\end{abstract}

Keywords: Temperature, Time series forecasting, Machine learning, Deep learning, LSTM, ARIMA.

* Sorumlu Yazar: sevnc.aynur03@gmail.com 


\section{Giriş}

Önemli bir meteorolojik parametre olan hava sıcaklığı; enerji, tarım, ekoloji ve hidroloji gibi birçok alanda büyük önem taşımaktadır. Hava sıcaklığı tahmini, meteoroloji alanındaki araştırmacılar ve tahminciler için önemli bir görevdir. Son yıllarda, hava sıcaklığını doğru bir şekilde tahmin etme hedefi; bulanık teori, makine öğrenimi ve istatistiksel yöntemler gibi sayısız konsepte dayalı buluşsal güdümlü modellerin uygulanmasını zorunlu kılmıştır [1].

Yapay sinir ağları (YSA) ve temeli bu sinir ağlarına dayanan derin öğrenme gibi yapay zeka modelleri (AI) hava tahminlerinde başarılı uygulamalar gerçekleştirmektedir. Yapay sinir ağları, insan beyninin yapısından esinlenilerek tasarlanan, örüntü tanıma ve hata minimizasyonuna dayalı bir yöntemdir. YSA matematiksel modellerle ilgili varsayımsal önermeye ihtiyaç duymadığından, işlev yaklaşımı ve veri uyumu için geleneksel istatistiksel tekniklere etkili bir alternatif olduğu düşünülmektedir [2]. Başarılı tahminler büyük ölçüde YSA modellerinin eğitiminde kullanılan deneysel veri örneklerinin kalitesine (büyüklüğüne ve dağılımına) bağlıdır [3]. YSA'lar, sürecin kapsamlı bir şekilde anlaşılmasına gerek olmadan karmaşıklığın önemli ölçüde azaltılmasına, tahmin doğruluğunun artırılmasına ve daha genel ve esnek modellerin elde edilmesine izin verir.

Makineler daha zeki nasıl olabilir? sorunsalından hareketle geliştirilen yapay zekâ (Artificial Intelligence) kısaca, makinelerin insandaki bilişsel ve öğrenme kabiliyetini taklit etmesi ve insana özgü olan akıl yürütme yeteneğini gerçekleştirmesi olarak tanımlanabilir. Say (2018) yapay zekâyı, doğal sistemlerin yapabildiği (zekice olsun veya olmasın) her bilişsel etkinliği (gerekirse bedenleri olan) yapay sistemlere, daha da yüksek başarım düzeylerinde nasıl yaptırabileceğimizi inceleyen bilim dalı olarak tanımlamaktadır. Makine öğrenimi, bilgisayarın özel olarak tasarlanmış programlar ve algoritmalarla gösterdiği zekayı ifade eden AI'nın alt kümesidir. Daha geniş bir tanımla, bilgisayar ortamında verilen her bir örnekten gerekli algoritma ve formülasyonların kullanılmasıyla bir şeyler öğrenilmesi aracılığıyla ilerleyen zaman ya da zamanlar için ilgilenilen olay hakkında karar verecek düzeye ulaşılmasına makine öğrenmesi denilmektedir [4]. Farklı makine öğrenme algoritmaları mevcuttur. En yeni öne çıkan örnekler, zekanın programda ve algoritma tasarımında insan akıl yürütme sürecini taklit ederek elde edildiği derin öğrenme modeli olacaktır [5]. Derin öğrenme ile yapay sinir ağları arasındaki temel fark, derin öğrenmede sinir ağlarındaki gizli katmanların derinliğinin katlanarak artan karmaşıklığıdır. Derin öğrenme modeli, genellikle milyonlarca bağlantılı nöron içeren insan beynindeki karmaşık nöron yapısına daha fazla benzerlik göstermektedir. Yapay zeka, makine öğrenmesi ve derin öğrenme arasındaki ilişki Şekil 1 ile şematize edilmiştir.

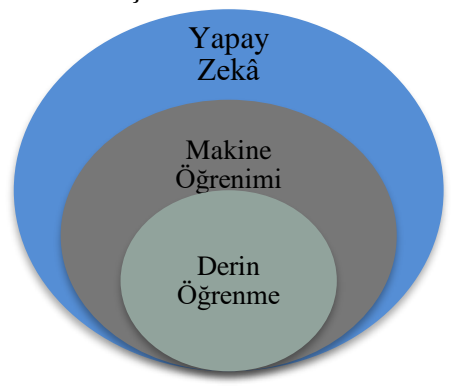

Yapay zeka modellerinden derin öğrenme, tahmin çalışmalarında yaygın olarak kullanılmaktadır. Derin öğrenme, büyük veri araştırmalarında, kalıpları otomatik ve etkili bir şekilde tanımak ve denetimsiz/denetimli modeller aracılığıyla karmaşık verilerdeki bilgileri keşfetmek için kullanılan verimli bir teknolojidir [6]. Son zamanlarda derin inanç ağı $(\mathrm{DBN})$, tekrarlayan sinir ağı $(\mathrm{RNN})$ ve uzun kısa süreli bellek (LSTM) kullanılarak hava sıcaklığını analiz etmek için bazı derin öğrenmeye dayalı stratejiler önerilmiştir. Geleneksel yapay zeka yöntemleri, yalnızca doğal verileri ham haliyle işleyebilir. LSTM gibi son teknoloji derin ögrenme (DL) yöntemleri, temel veri kalıplarını keşfetmek için birden çok işleme katmanından oluşan hesaplama algoritmalarına olanak tanımaktadır. Bununla birlikte, zaman serisi analizi çalışmalarında sıklıkla tercih edilen bir diğer model ARIMA modelidir. Çoğunlukla istatistiki hesaplamalara dayanan ARIMA modelleri ile makine öğrenmesine dayalı yöntemler kullanılmaktadır. ARIMA modelleri bazı önemli kısıtlamalara sahiptir, bu kısıtlamaların çözümü olarak zaman serisi analizleri için derin öğrenmeye dayalı yeni yöntemler geliştirilmiştir.

Konuyla ilgili yapılmış çalışmalara bakıldığında; Tatlı ve Şen (1999) [7] çalışmalarında, zaman serisi verilerini kullanarak maksimum günlük sıcaklığı tahmin etmek için bulanık teoriyi benimsemişlerdir. Bilgili ve Şahin (2010) [8], Türkiye'deki uzun vadeli aylık sıcaklıkları tahmin etmek için YSA'yı kullanmıştır. Liu ve arkadaşları (2015) [9], geniş bir zaman periyodu boyunca saatlik hava durumu verilerini simüle etmek için Stacked AutoEncoder adlı derin bir sinir ağı kullanmıştır. Bu modelin Yığılmış Gürültü Giderici Otomatik Kodlayıcı olarak bilinen bir varyantının, basınç, nem ve rüzgar hızı gibi diğer hava değişkenlerinin hesaba katıldığı hava sıcaklığını tahmin etmek için standart birçok katmanlı ileri beslemeli sinir ağından daha iyi performans sergilediği gösterilmiştir. Soares ve arkadaşları (2018) [10], sırasıyla belirli bir zaman periyodunda hava ve yağış tahmininde bulunmak için zaman serisi modellemesini uygulamışlardır. Vantuch ve Zelinka (2015) [11] ise, ARIMA modelinin oluşturulması ve tahmin edilmesi için evrim algoritmalarını kullanmışlardır.

$\mathrm{Bu}$ çalışmanın birincil amacı, ortalama hava sıcaklığı verilerini kullanarak gelecek hava sıcaklığı tahmini için bir derin öğrenme modeli olan LSTM ve istatistiksel analiz ARIMA modellerinin doğruluğunu değerlendirmektir. Çalışmanın ikinci amacı ise, bu modellerin gerçeğe yakın değerler elde etmede performans ölçütlerinin karşılaştırılmasıdır. Çalışmanın ilerleyen bölümlerinde; veri ve yöntemlerin ayrıntılı açıklaması, makalenin deneysel sonuçları ve son olarak genel sonuç bilgilerine yer verilmiştir.

\section{Materyal ve Metot}

\section{1. Çalışma Alanı ve Mevcut Veriler}

Çalışma alanımız, Türkiye'nin Doğu Anadolu Bölgesi'nin Yukar1 Firat bölümünde yer alan Bingöl iline bağlı Solhan İlçesi'dir (Şekil 2). Bingöl ili $41^{\circ} 20$ ve $39^{\circ}-56^{\circ}$ doğu boylamları ile $39^{\circ}-31$ ve $36^{\circ}-28^{\circ}$ kuzey enlemleri arasında yer alan coğrafi konuma sahiptir. Çalışma alanımızı oluşturan Solhan ilçesi il merkezine $60 \mathrm{~km}$ uzaklıktadır. Ayrıca bölge için önemli bir turistik doğa harikası sayılan Yüzen Adalar Solhan ilçesinin sınırları içerisindedir. Meteoroloji İşleri Genel Müdürlüğü’nün sunduğu verilere göre Bingöl'ün yıllık ortalama sıcaklığı 12.1 derecedir.

Şekil 1. Yapay zekâ unsurları 


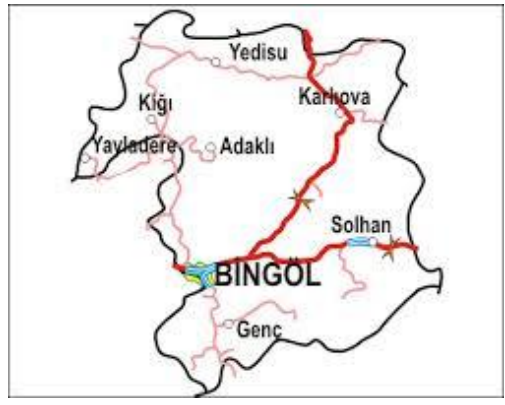

Şekil 2. Türkiye Bingöl ili haritası

$\mathrm{Bu}$ çalışmada kullanılan veriler Meteoroloji Genel Müdürlüğü'nden resmi yazışma yoluyla elde edilmiştir. Meteorolojik Veri Bilgi Sunum ve Satış Sistemi'nden (MEVBİS) alınan veri kümesi seti, Bingöl'ün Solhan ilçesinin 2014 ile 2020 yılları arasını kapsayan her yılın 12 ayına ait günlük ortalama sıcaklıklarını içermektedir. Veriler, belirtilen tarihler arasında toplam 2306 günlük gözlemden oluşmaktadır. 1 Ocak 2014 ile 27 Nisan 2020 tarihleri arasını içeren veriler Microsoft Excel programı kullanılarak düzenlenmiştir. Aylık ortalama sicaklık değerleri hesaplanarak aşağıda yer alan Tablo 1'de veri setine ait değerler sunulmuştur.

Tablo 1. Veri setinde mevcut ham veriler ve hesaplanan aylık ortalama sıcaklık değerleri

\begin{tabular}{c|c|c|c|c|c}
\hline No & Yıl & Ay & Gün & $\begin{array}{c}\text { Sicaklık } \\
\left({ }^{\circ} \mathbf{C}\right)\end{array}$ & $\begin{array}{c}\text { Aritmetik } \\
\text { Ortalama }\end{array}$ \\
\hline 1 & 2014 & 1 & 1 & -1.0 & -4.56 \\
\hline 2 & 2014 & 1 & 2 & -4.9 & -4.56 \\
\hline 3 & 2014 & 1 & 3 & -4.9 & -4.56 \\
\hline 4 & 2014 & 1 & 4 & -6.2 & -4.56 \\
\hline$\cdot$ & $\cdot$ & $\cdot$ & $\cdot$ & $\cdot$ & $\cdot$ \\
\hline$\cdot$ & $\cdot$ & $\cdot$ & $\cdot$ & $\cdot$ & $\cdot$ \\
\hline 2304 & 2020 & 4 & 25 & 9.1 & 9.68 \\
\hline 2305 & 2020 & 4 & 26 & 10.0 & 9.68 \\
\hline 2306 & 2020 & 4 & 27 & 10.8 & 9.68 \\
\hline
\end{tabular}

Tablo 1'e bakıldığında yıllara ve aylara göre sicaklık değerlerinin dağılımı görülmektedir. Veri kümesinde mevcut hava sıcaklığ 1 değerleri minumum $-12^{\circ} \mathrm{C}$ ile maksimum $31.2^{\circ} \mathrm{C}$ arasında değişmektedir. Şekil 3, veri setinin yıllara göre aylık ortalama sicaklık değerlerini göstermektedir.

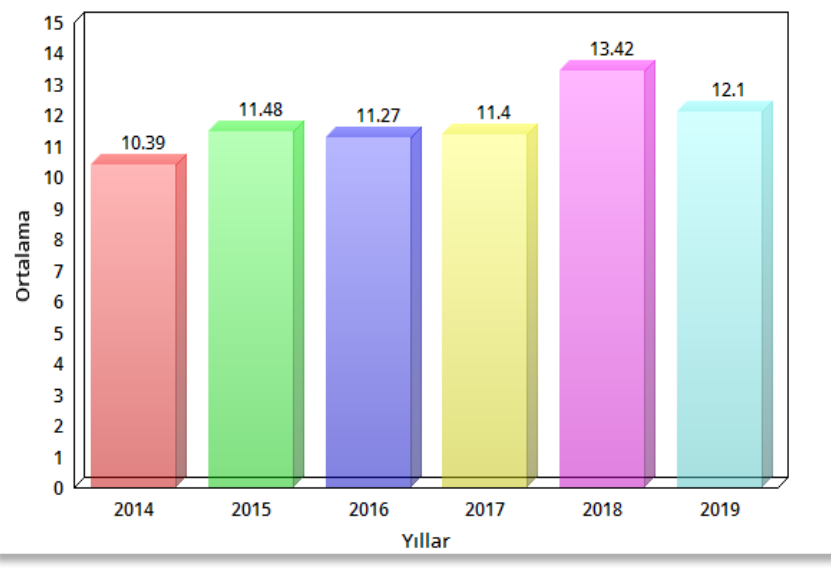

Şekil 3. 2014-2020 arası yıllık ortalama sıcaklık değerleri

Şekil 3'te yer alan grafik incelendiğinde, her yıla ait ortalama sıcaklık değerleri dağılımında en düşük ortalama sıcaklığın 2014 yılı, en yüksek sıcaklığın ise 2018 yılına ait olduğu görülmektedir.

\section{2. Önerilen Yöntem}

Uygulanacak probleme göre birçok derin öğrenme mimarisi mevcuttur. Bunlardan bazıları; Konvolüsyonel sinir ağları (CNN), Tekrarlayan sinir ağları (RNN), Uzun kısa süreli hafıza ağları (LSTM), Sinırlı boltzman makineleri (RBM), Derin oto kodlayıcılardır [12]. Derin öğrenme kütüphaneleri; Caffe2, BilişselAraç Seti, Matlab, Mxnet, Nvıdıa Caffe,Pytorch, Tensorflow, Chainer, PaddlePaddle'dır.

$\mathrm{Bu}$ çalışmada, bir derin öğrenme modeli olan LSTM ile durağan zaman serileri tahmini için yaygın olarak kullanılan bir istatistiksel yaklaşım olan ARIMA modeli kullanılmıştır. ARIMA modellerinde yer alan üç ana adım; adım 1 model tanımlama, adım 2 parametre tahmini ve adım 3 teşhis kontrolüdür [13]. Çalışmamızın diğer modeli ise tekrarlayan sinir ağının (RNN) özel bir şekli ve bir makine öğrenme algoritması olan LSTM'dir. LSTM modeli tahmin çalışmalarında sıklıkla kullanılmaktadır. Yapay zeka ve bilimsel hesaplama uygulamalarında son on yılda oldukça popüler olan ve zengin kütüphanelere sahip Python programlama dilinin Python $3 \mathrm{x}$ serisine ait 3.8 sürümü kullanılarak Anaconda platformu üzerinden Spyder arayüzü ile analiz işlemleri gerçekleştirilmiştir. Programın verileri okuyabilmesi için Excel dosyası .csv (virgülle ayrılmış değerler dosyası) formatına çevrilmiş ve arayüz programına import edilmiştir.

\subsection{Modelin Teorik Arka Planı}

\subsubsection{Uzun Kısa Süreli Bellek (LSTM)}

Bellek ağları (LSTM) bilgileri uzun süre tutabilirler. Ortak bir LSTM birimindeki bilgi akışı, hücre durumu tarafından kontrol edilir ve bilginin hücre durumuna geçmesine izin verilip verilmeyeceğini üç kapı kontrol eder. LSTM'ler, zaman serisi verilerine (hava durumu verileri vb.) dayalı tahminler yapmak için çok iyi çalışsa da daha fazla belleğe ihtiyaç duyarlar ve daha fazla parametreye sahip oldukları için eğitilmeleri çok uzun sürer [14].

Uzun Kısa Süreli Bellek (LSTM), sıralı verileri öğrenme ve tahmin etme konusunda güçlü bir yeteneğe sahip bir tür tekrarlayan sinir ağıdır. Araştırmalar sonucunda, RNN'nin 
sınırlı olduğu kabul edilmiş ve bu sınırlamanın üstesinden gelmek için, zaman içinde durumunu koruyabilen, neyin hatırlanacağına, neyin unutulacağına ve neyin çıkarılacağına karar veren kapılarla birlikte bellek yapısı eklenerek LSTM geliştirilmiştir.

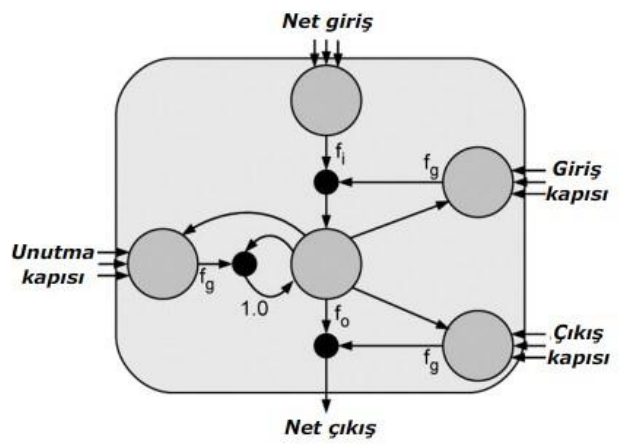

Şekil 4. Bir bellek hücresinden oluşan LSTM bellek bloğu

LSTM mimarisi genellikle giriş, unutma ve çıkış kapıları gibi üç kapı içerir (Şekil 4). Giriş kapısı, verilerin giriş akışını kontrol etmek için kullanılırken, çıkış kapısı, verilerin bellek hücrelerine çıkışını kontrol etmek için kullanılır. Unutma kapısı ise, son bellek hücresinden mevcut bellek hücresine hangi bilgilerin geçtiğini kontrol etmek için kullanılır. Bu kapılar formülasyonlarıyla birlikte aşağıda sırasıyla detaylı olarak açıklanmıştır [15].

Giriş Kapısı: Hücre durumuna bazı yararlı bilgilerin eklenmesi çoğunlukla giriş kapısı ile yapılır. İlk olarak, bilgi sigmoid işlevi kullanılarak toplanır ve $x(t)$ ve $h(t-1)$ girişlerini kullanarak unutma kapısına benzer hatırlanan değerleri filtreler. Ardından, $x(t)$ ve $h(t-1)^{\prime}$ den gelen tüm olası değerleri içeren -1 'den +1 'e çıktı veren $\tan h$ işlevi kullanılarak bir vektör elde edilir. Son olarak, yararlı bilgiyi elde etmek için vektörün değerleri ve düzenlenmiş değerler çarpılır.

Unut Kapısı: Hücre durumunda artık kullanılmayan bilgi, unutma kapısıyla birlikte çekilir. İki giriş $x(t)$ ve $h(t-1)$ kapıya beslenir ve bunlara karşılık gelen ağırlık matrisleriyle çarpılır ve ardından küçük sapma değeri eklenir.

Çıkış Kapısı: Mevcut hücre durumundan faydalı bilgilerin çıkarılması işi bir çıktı olarak kabul edilir. İlk olarak, hücre üzerinde $\tan \mathrm{h}$ fonksiyonu kullanılarak bir vektör oluşturulur. Ardından, bilgi çeşitli sigmoid işlevi kullanılarak düzenlenir ve $x(t)$ ve $h(t-1)$ girişleri kullanılarak hatırlanacak tüm değerleri filtreler. Son olarak, vektörün değerleri ve düzenlenmiş değerler, bir sonraki hücreye çıktı ve girdi üretmek için çarpilır.

LSTM'nin en yaygın varyantı şu şekilde tanımlanır:

$$
\begin{aligned}
& \mathbf{f}_{t}=\sigma\left(\mathbf{W}_{f h} \mathbf{h}_{t-1}+\mathbf{W}_{f x} \mathbf{x}_{t}+\mathbf{b}_{f}\right), \\
& \mathbf{i}_{t}=\sigma\left(\mathbf{W}_{i h} \mathbf{h}_{t-1}+\mathbf{W}_{i x} \mathbf{x}_{t}+\mathbf{b}_{i}\right), \\
& \mathbf{o}_{t}=\sigma\left(\mathbf{W}_{o h} \mathbf{h}_{t-1}+\mathbf{W}_{o x} \mathbf{x}_{t}+\mathbf{b}_{o}\right), \\
& \tilde{\mathbf{c}}_{t}=\tanh \left(\mathbf{W}_{c h} \mathbf{h}_{t-1}+\mathbf{W}_{c x} \mathbf{x}_{t}+\mathbf{b}_{c}\right), \\
& \mathbf{c}_{t}=\mathbf{f}_{t} \odot \mathbf{c}_{t-1}+\mathbf{i}_{t} \odot \tilde{\mathbf{c}}_{t}, \\
& \mathbf{h}_{t}=\mathbf{o}_{t} \odot \tanh \left(\mathbf{c}_{t}\right) .
\end{aligned}
$$

Formülasyonda; $c_{t}$ unutma kapısına göre sıfırlanan, üzerine yazılan ve okunan $f_{t}$, giriş kapısı $i_{t}$ ve çıkış kapısı $o_{t}$ olarak kabul edilir. Özellikle, her üç kapı da basit RNN'lere çok benzerdir, ancak temel fark, tanh aktivasyon fonksiyonu yerine sigmoid aktivasyon fonksiyonu vardır (Çıktıları 0 ile 1 arasında sinırlandirmak).

\subsubsection{Otoregresif Entegre Hareketli Ortalama (ARIMA)}

Otomatik Regresif Entegre Hareketli Ortalama modeli veya ARIMA, bir değişkenin gelecekteki değerini kendi geçmiş değerlerinden tahmin etmede kullanılan bir zaman serisi tahmin yaklaşımıdır. Otomatik regresyon ve hareketli ortalama kullanır ve trendi ve/veya mevsimselliği ortadan kaldırmak için bir fark sıralaması içerir. Model aşağıdaki denklemle ifade edilir:

$$
y_{t}=c_{t}+\sum_{i=1}^{p} \phi_{m} y_{t-i}+\sum_{j=1}^{q} \theta_{n} e_{t-j}
$$

ARIMA modeli 3 parametre içerir $(p, d, q)$. Parametre $p$, ARIMA modelinde, gecikecek dönemleri temsil eder. Örneğin, bir değer $\mathrm{p}=2$, denklemin otomatik regresyon kısmında zaman serisinin önceki 2 zaman diliminin kullanıldığını gösterir. Parametre d trendi ve/veya mevsimselliği ortadan kaldırmak için yapılan farklılaştırma dönüşümlerinin sayısını temsil eder, bu nedenle zaman serisini durağan bir seriye dönüştürür, yani ortalama ve varyansı zaman içinde sabit hale getirir. $\mathrm{Bu}$, verileri bir ARIMA modelinde kullanıma hazırlamak için önemli bir adımdır. Parametre q ise, ARIMA modelinin hata bileşeninin gecikmesini temsil eder. Hata bileşeni, zaman serisinin trend veya mevsimsellik ile açıklanamayan kısmıdır [16].

\subsubsection{Hata Kriteri Ölçütleri}

Hata kriter ölçütleri olarak; Hata Kareleri Ortalamasının Karekökü (RMSE), Ortalama Mutlak Hata (Mean Absolute ErrorMAE),_Ortalama Kare Hata (Mean Squared Errors-MSE) ve R ${ }^{2}$ (Korelasyon Katsayısı) kullanılmıştır. $\mathrm{Bu}$ ölçütler formülasyonuyla birlikte aşağıda detaylı olarak açıklanmaktadır.

RMSE: Kök ortalama kare hata (RMSE), tahmin edilen $\hat{y i}$ değerlerinde hata kareler ortalaması karekökü olup en önemli performans ölçütlerinden birisidir [17]. Denklem 8'de RMSE formülü verilmiştir. Burada, $y_{i}$ gerçek veriyi $\widehat{y}_{l}$ parametresi ise tahmin edilen değerlerini göstermektedir.

$$
R M S E=\sqrt{\frac{\sum_{\mathrm{i}=1}^{n}\left(y_{i}-\widehat{y_{l}}\right)^{2}}{n}}
$$


MSE: Ortalama kare hata (MSE), tahminleyicinin performansını ölçen kriterdir. Her zaman pozitif değer alır ve MSE değeri sıfıra ne kadar yakınsa tahminleyicinin o ölçüde iyi performans gösterdiği yorumu yapılabilir.

$$
M S E=1 / N \sum_{i=1}^{N} e_{i}^{2}=1 / N \sum_{i=1}^{N}\left(t_{i}-a_{i}\right)^{2}
$$

$\boldsymbol{M A E}$ : Ortalama Mutlak Hata (MAE), doğrusal bir skordur ve iki sürekli değişsken arasındaki farkın ölçüsünü ifade etmektedir. Bu değer 0'dan $\infty$ 'a kadar değişim gösterebilir. Burada $t$ beklenen değeri, a ise gerçek ölçüm değerini temsil etmektedir.

$$
M A E=1 / N \sum_{i=1}^{N}\left|t_{i}-a_{i}\right|
$$

$\boldsymbol{R}^{2}$ : Gerçek değerler ile tahmin edilen değerler arasındaki ilişkiyi ifade eden $\mathrm{R}$ kare skoru, 0-1 arasında değer alır. $R^{2}$ değeri 1'e ne kadar yakınsa model o kadar hassas ve uyum iyiliği uygun demektir. Denklem 11 'de $\mathrm{R}^{2}$ formülü yer almaktadır.

$$
R=\frac{\sum(\mathrm{x}-\bar{x})(y-\bar{y})}{\sum(\mathrm{x}-\bar{x})^{2} \sum(\mathrm{y}-\bar{y})^{2}}
$$

\section{Araştırma Sonuçları}

\subsection{Bulgular}

Model eğitimi için tüm veri seti bir anda eğitime katılmaz. İlk parça eğitildikten sonra modelin başarısına bakılır, başarım performansına göre geriyayılım ile ağırlıkların güncellenmesi yapılır. Sonraki adımda yeni eğitim kümesi belirlenir ve model eğitimi tekrar yapılarak ağırlıklar yeniden güncellenir. Her eğitim adımında bu işlem tekrarlanarak modele en uygun ağırlık değerlerinin hesaplanması hedeflenir. Bu eğitim aşamalarının her biri "epoch" (eğitim döngü sayısı) olarak adlandırılmaktadır. Epoch sayısının artması modelin başarımını da artırmaktadır. RNN ve özel bir türü olan LSTM gibi derin öğrenme ağlarında epoch sayısı diğer modellere kıyasla daha yüksek tutulmalıdır. Başarı düzeyi belirli bir epoch değerinden sonra çok küçük miktarda artış sergileyeceği için bu noktalarda eğitimin sonlandırılması gerekebilir [18].

Veri kümesi seti fazla değişkenlik gösteriyorsa başarım grafiği inişli çıkışlı olabilir. Verinin değiştirilme şansının olmadığı zamanlarda batch değeri değiştirilerek sorun giderilmektedir. Batch aşamasında, veri kümesi batch değeri olarak verilen değere göre parçalara ayrılır ve her iterasyonda model eğitimi bu parça üzerinden yapılır. Batch seçilirken verilerin rastgele seçilmesine önem gösterilmelidir.

Probleme, veri kümesi seti vb. gibi faktörlere bağlı kalınarak derin öğrenme modelini tasarlayan kişi en uygun nöron değerini de belirlemektedir. Bu çalışmada derin öğrenme modeline ait parametrelerden; Epochs, Batch ve Nöron sayılarında yapilan farklı denemeler sonucunda en iyi sonuç; 80 epoch, 1 batch ve 80 nöron alınarak bulunmuş yani gerçek değerlere en yakın tahmin değerleri elde edilmiştir. Şekil 5'te LSTM derin öğrenme modeli ile elde edilen gerçek değerler ile tahmini değerlere ait grafik gösterilmektedir.

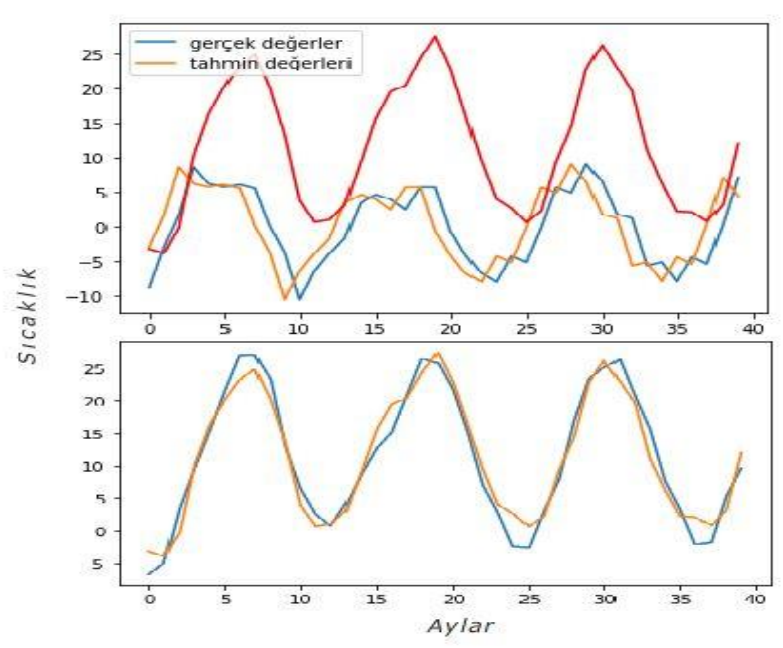

Şekil 5. LSTM modeli ile Solhan ilçesi sıcaklık tahmini grafiği

Şekil 5 'te yer alan grafikler incelendiğinde, derin öğrenme modeli LSTM ile yapılan zaman serisi analizleri sonucunda hava sıcaklığı tahmini değerlerin gerçek değerlere yakın bulunduğu gözlenmektedir.

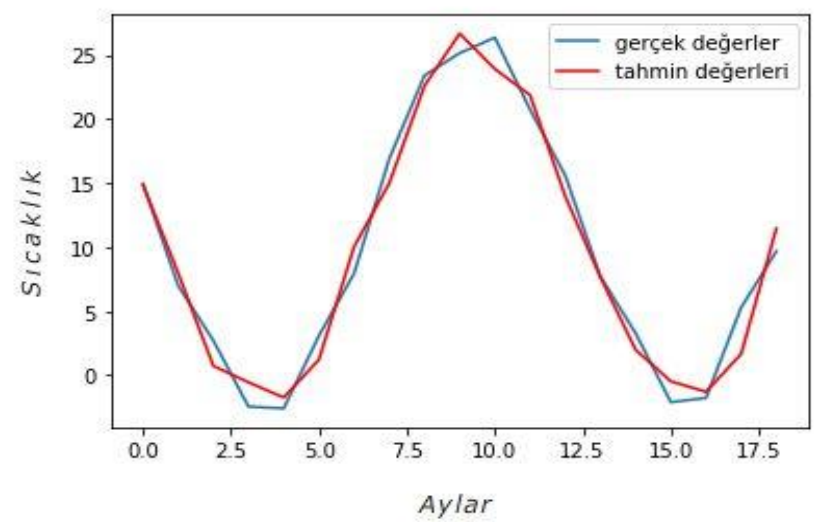

Şekil 6. ARIMA modeli ile Solhan ilçesi sıcaklık tahmini grafiği

Şekil 6'da yer alan grafik incelendiğinde, bir istatistiksel modelleme yöntemi olan ARIMA ile yapılan analizler sonucunda hava sıcaklığı tahmini değerlerin gerçek değerlere yakın bulunduğu görülmektedir.

Çalışmamızın birincil amacı, ortalama hava sıcaklığı verilerini kullanarak gelecek hava sıcaklığı tahmini için bir derin öğrenme modeli olan LSTM ve istatistiksel ARIMA modellerinin doğruluğunu değerlendirmekti. Bu kapsamda Tablo 2'de Solhan ilçesinde ölçülen gerçek sıcaklık değerleri ile ARIMA ve LSTM modeliyle tahminlenen sıcaklık değerleri karşılaştırmalı olarak sunulmaktadır.

Tablo 2. Ölçülen gerçek sıcaklık değerleri, LSTM ve ARIMA ile tahmin edilen sıcaklık değerleri

\begin{tabular}{l|c|c|c}
\hline Tarih & $\begin{array}{c}\text { Aylık Ortalama } \\
\text { Gerçek Sıcaklık } \\
\text { Değeri }\left({ }^{\circ} \mathbf{C}\right)\end{array}$ & $\begin{array}{c}\text { ARIMA } \\
\text { Modeli ile } \\
\text { Tahmin } \\
\left({ }^{\circ} \mathbf{C}\right)\end{array}$ & $\begin{array}{c}\text { LSTM } \\
\text { Modeli ile } \\
\text { Tahmin } \\
\left({ }^{\circ} \mathbf{C}\right)\end{array}$ \\
\hline Ekim 2018 & 14.96 & 14.86 & 15.97 \\
\hline Kasım 2018 & 6.99 & 7.97 & 9.13 \\
\hline Aralık 2018 & 2.71 & 0.72 & 3.69 \\
\hline Ocak 2019 & -2.45 & -0.55 & 2.49 \\
\hline
\end{tabular}




\begin{tabular}{l|c|c|c}
\hline Şubat 2019 & -2.58 & -1.73 & 0.67 \\
\hline Mart 2019 & 3.09 & 1.22 & 2.22 \\
\hline Nisan 2019 & 7.95 & 10.04 & 9.31 \\
\hline Mayıs 2019 & 16.92 & 15.00 & 14.50 \\
\hline Haziran 2019 & 23.41 & 22.59 & 22.90 \\
\hline Temmuz 2019 & 25.15 & 26.68 & 26.44 \\
\hline Ağustos 2019 & 26.37 & 23.91 & 23.36 \\
\hline Eylül 2019 & 20.75 & 21.87 & 19.99 \\
\hline Ekim 2019 & 15.60 & 13.97 & 11.45 \\
\hline Kasım 2019 & 7.70 & 7.66 & 6.59 \\
\hline Aralık 2019 & 3.29 & 1.99 & 2.57 \\
\hline Ocak 2020 & -2.10 & -0.46 & 2.24 \\
\hline Şubat 2020 & -1.77 & -1.28 & 0.84 \\
\hline Nisan 2020 & 9.68 & 11.46 & 11.77 \\
\hline
\end{tabular}

Tablo 2'de yer alan gerçek ve tahmini hava sıcaklığı değerleri incelendiğinde, LSTM ve ARIMA ile yapılan analiz sonucunda tahmini değerlerin gerçek değerlere yakın olduğu görülmektedir.

Çalışmamızın ikinci amacı ise, bu modellerin gerçeğe yakın değerler elde etmede performans ölçütlerinin karşılaştırılmasıydı. Bu kapsamda belirli bir algoritmanın/modelin çalışma türü ve güvenilirliği hakkında bize kanıt sağlayan özel formüllerden oluşan hata kriteri ölçütleri ile derin LSTM modelinde ve bir zaman serisi tahmin analizi sunan ARIMA modelinde ayrı olarak hesaplanmış ve grafik ile karşılaştırmalı olarak sunulmuştur (Şekil 7, Şekil 8).

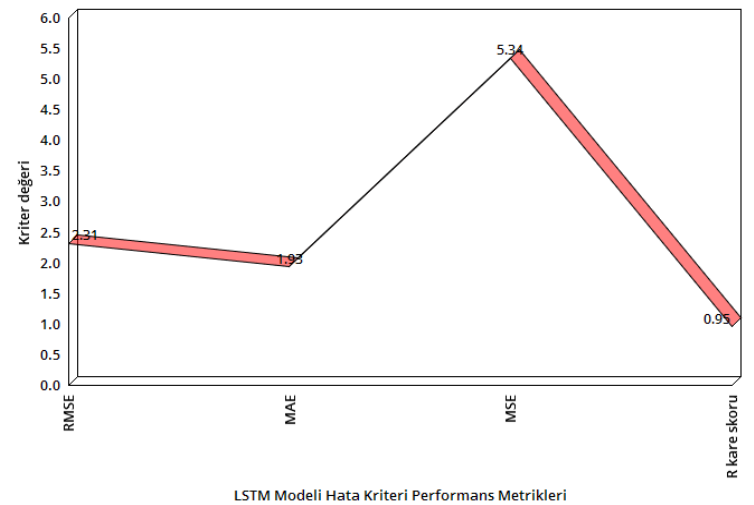

Şekil 7. Derin LSTM modelinde hata kriteri değerleri

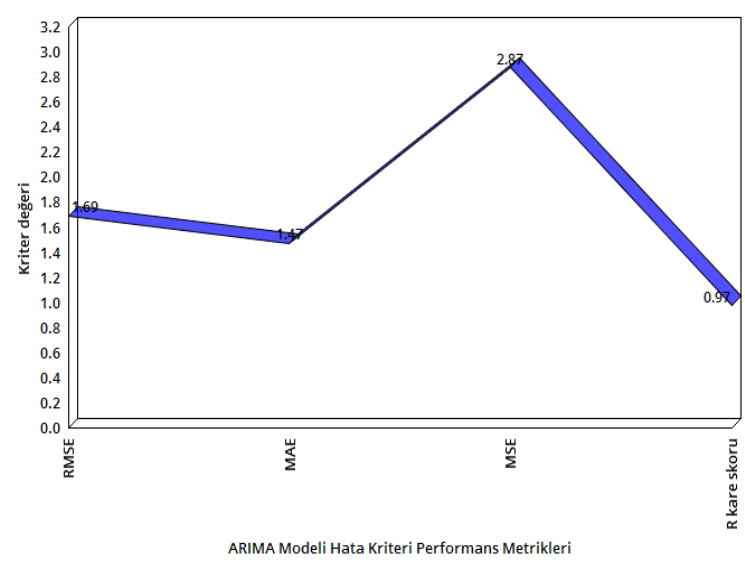

Şekil 8. ARIMA modelinde hata kriteri değerleri
Şekil 7 ve Şekil 8'de yer alan grafikler incelendiğinde; LSTM modelinde MAE 1.930, MSE 5.344, RMSE 2.312 ve R kare skoru değeri 0.95 olarak hesaplanmıştır. ARIMA modelinde ise; MAE 1.478, MSE 2.877, RMSE 1.696 ve R kare skoru değerinin 0.97 olduğu görülmektedir.

\section{Sonuç}

$\mathrm{Bu}$ araştırma Bingöl'ün Solhan ilçesini çalışma alanı olarak belirleyerek, LSTM ve ARIMA modellerinin hava sıcaklığını tahmin etmedeki doğruluğunu test etmeyi ve iki model arasında performans karşılaştırması yapmayı amaçlamıştır. Seçilen modelin veri seti ile uyum durumunu ifade eden $\mathrm{R}$ kare skoru değerinin LSTM modelinde 0.95, ARIMA modelinde ise 0.97 olarak bulunması, veri setimiz için en uygun modellerin seçildiğini göstermektedir. Seçilen modeller RMSE, MAE, MSE gibi doğruluk ölçütleri açısından incelenmiştir. En önemli performas ölçüt kriterlerinden biri olarak kabul edilen RMSE değeri ARIMA modelinde 1.696, LSTM modelinde ise 2.312 olarak bulunmuştur. RMSE metriğinin sıfir değerini alması modelin hiç hata yapmadığı anlamına gelmektedir. Performans karşılaştırması yapıldığında, doğruluk ölçüt değerlerinin iki modelde de yüksek doğrulukta olduğu görülmüştür. Derin öğrenme modeli LSTM ve istatistiki model ARIMA'nın sıcaklık serisi tahmininin doğruluğu uygun ve tatmin edicidir. Gelecekteki çalışmalar, çok değişkenli, çok adımlı ve çok bölgeli bir hava durumu tahmin problemi oluşturmak için daha fazla konumun dahil edilmesini ve daha karmaşık derin öğrenme tabanlı tahmin modelleri kullanımını içerebilir.

\section{Teşekkür}

$\mathrm{Bu}$ bilimsel çalışma sürecini gerçekleştirmek için gerekli verilerin kullanımına izin veren T.C. Meteoroloji Genel Müdürlüğü'ne teşekkürü borç biliriz.

\section{Kaynakça}

[1] Yu, X., Shi, S., \& Xu, L. (2021). A spatial-temporal graph attention network approach for air temperature forecasting. Applied Soft Computing, 107888.

[2] Rahman, A. A., \& Zhang, X. (2018). Prediction Of Oscillatory Heat Transfer Coefficient For A Thermoacoustic Heat Exchanger Through Artificial Neural Network Technique. International Journal of Heat and Mass Transfer, 124, 1088-1096.

[3] Haykin, S. (2010). Neural Networks and Learning Machines, $3 / E$. Pearson Education India.

[4] Öztemel, E. (2012). Yapay Sinir Ağları (3.Bask1). İstanbul: Papatya Yayıncilik.

[5] He, K., Ji, L., Wu, C. W. D., \& Tso, K. F. G. (2021). Using SARIMA-CNN-LSTM approach to forecast daily tourism demand. Journal of Hospitality and Tourism Management, 49, 25-33.

[6] Torres, J. F., Hadjout, D., Sebaa, A., Martínez-Álvarez, F., \& Troncoso, A. (2021). Deep Learning for Time Series Forecasting: A Survey. Big Data, 9(1), 3-21.

[7] Tatl1, H., \& Şen, Z. (1999). A new fuzzy modelling approach for predicting the maximum daily temperature from a time series. Turkish Journal of Engineering and Environmental Sciences, 23(3), 173-180. 
[8] Bilgili, M., \& Sahin, B. (2009). Prediction of long-term monthly temperature and rainfall in Turkey. Energy Sources, Part A: Recovery, Utilization, and Environmental Effects, 32(1), 60-71.

[9] Liu, J.N., Hu, Y., He, Y., Chan, P.W., Lai, L. (2015). Deep neural network modeling for big data weather forecasting, in: Information Granularity, Big Data, and Computational Intelligence. Springer, pp. 389-408.

[10] Soares, E., Costa Jr, P., Costa, B., \& Leite, D. (2018). Ensemble of evolving data clouds and fuzzy models for weather time series prediction. Applied Soft Computing, 64, 445-453.

[11] Vantuch, T., \& Zelinka, I. (2015). Evolutionary based ARIMA models for stock price forecasting. In ISCS 2014: Interdisciplinary Symposium on Complex Systems (pp. 239247). Springer, Cham.

[12] Süzen,A.A.,,Kayaalp,K.,Derin Öğrenme Yöntemleri İle Sıcaklık Tahmini: Isparta İli Örneği,Internatıonal Academıc, Research Congress, 2018.

[13] Eze, N., Asogwa, O., Obetta, A., Ojide, K., \& Okonkwo, C. (2020). A time series analysis of federal budgetary allocations to education sector in Nigeria (1970-2018). American Journal of Applied Mathematics and Statistics, 8(1), 1-8.

[14] Roy, D. S. (2020). Forecasting the Air Temperature at a Weather Station Using Deep Neural Networks. Procedia Computer Science, 178, 38-46.

[15] Nisha, S. S., Sathik, M. M., \& Meeral, M. N. (2021). Application, algorithm, tools directly related to deep learning. In Handbook of Deep Learning in Biomedical Engineering (pp. 61-84). Academic Press.

[16] Alabdulrazzaq, H., Alenezi, M. N., Rawajfih, Y., Alghannam, B. A., Al-Hassan, A. A., \& Al-Anzi, F. S. (2021). On the accuracy of ARIMA based prediction of COVID-19 spread. Results in Physics, 27, 104509.

[17] Demirezen, S. (2020). Türkiye'de Gün Öncesi Piyasası Iç̧in Elektrik Fiyatlarının Tahmini. Hacettepe Üniversitesi Fen Bilimleri Enstitüsü,Yüksek Lisans Tezi, Ankara.

[18] Çarkacı, N. (2018). Derin Öğrenme Uygulamalarında En Sık Kullanılan Hiper-parametreler. İnternet Adresi: https://medium.com/deep-learning-turkiye/derin-ogrenmeuygulamalarinda-en-sik-kullanilan-hiper-parametrelerece8e9125c4 Erişim tarihi: 15.10.2021 